\title{
Quantification of Anisakis simplex Allergens in Fresh, Long-Term Frozen, and Cooked Fish Muscle
}

\author{
Ana Isabel Rodríguez-Mahillo,' Miguel González-Muñoz,, Cristina de las Heras, ${ }^{3}$ \\ Margarita Tejada, ${ }^{3}$ and Ignacio Moneo ${ }^{2}$
}

\begin{abstract}
Fish-borne parasitic zoonoses such as Anisakiasis were once limited to people living in countries where raw or undercooked fish is traditionally consumed. Nowadays, several factors, such as the growing international markets, the improved transportation systems, the population movements, and the expansion of ethnic ways of cooking in developed countries, have increased the population exposed to these parasites. Improved diagnosis technology and a better knowledge of the symptoms by clinicians have increased the Anisakiasis cases worldwide. Dietary recommendations to Anisakis-sensitized patients include the consumption of frozen or wellcooked fish, but these probably do not defend sensitized patients from allergen exposure. The aim of our work was to develop a sensitive and specific method to detect and quantify Anisakis simplex allergens in fish muscle and its derivatives. Protein extraction was made in saline buffer followed by preparation under acid conditions. A. simplex antigens were detected by IgG immunoblot and quantified by dot blot. The allergenic properties of the extracts were assessed by IgE immunoblotting and basophil activation test. We were able to detect less than 1 ppm of A. simplex antigens, among them the allergen Ani s 4, in fish muscle with no cross-reactions and with a recovery rate of $82.5 \%$. A simplex antigens were detected in hakes and anchovies but not in sardines, red mullets, or shellfish. We detected $A$. simplex allergens in cooked hakes and also in hake stock. We proved that $A$. simplex allergens are preserved in long-term frozen storage $\left(-20^{\circ} \mathrm{C} \pm 2^{\circ} \mathrm{C}\right.$ for 11 months) of parasitized hakes. Basophil activation tests have proven the capability of the A. simplex-positive fish extracts to induce allergic symptoms.
\end{abstract}

\section{Introduction}

$\mathbf{T}$ He nematode ANISAKIS SIMPLEX, a parasite of fish and marine mammals, can cause gastrointestinal and allergic reactions in humans when larvae in the third developmental stage are eaten with infested fish and seafood. The main symptoms associated with the A. simplex allergy include urticaria, angioedema, vomiting, dyspnea, asthma, conjunctivitis, and even anaphylactic shock.

Food is the cause of $33 \%-50 \%$ of the anaphylactic episodes in the United States, Europe, Asia, and Australia (Brown et al., 2001; Sampson, 2003; Smith et al., 2005). Many of the patients suffering from food anaphylaxis declare that they were aware of their allergies before the life-threatening episodes, although they did not know that they were eating the cause of the allergy, as it was not declared on the food label (Bock et al., 2001; Clark et al., 2004; Uguz et al., 2005). These substances, present in foods in an insufficient proportion to be declared on the label but enough to elicit allergic reactions, are considered hidden allergens. In this way, $A$. simplex can be considered an important hidden allergen of fish and seafood, as it is the cause of $45.3 \%$ of the allergic food reactions and $58 \%$ of the anaphylactic reactions caused by hidden allergens in an adult population of Madrid (Spain) (Añíbarro et al., 2007). Each year, 50 new cases of anisakiasis are reported in the United States, 500 in Europe, and 2000 in Japan (Audicana and Kennedy, 2008).

Authors have debated largely whether parasitization of the patients' gastrointestinal tract by live larvae is necessary to develop allergic symptoms (Daschner et al., 2000; Audicana et al., 2002). Although an agreement has not been reached, there are a few reports about patients suffering allergic symptoms related to the consumption of canned or properly cooked fish, where the larvae are dead and, therefore, unable to parasitize the gastric tract (Audicana et al., 2002; Santaolalla, 2006; Moneo et al., 2007; Ventura et al., 2008). This is not surprising, due to the heat and pepsin resistance of some A. simplex allergens (Caballero and Moneo, 2004). To date, it has been impossible to reproduce any allergic symptom in provocation tests, using either frozen or lyophilized larvae, or larvae protein extracts (Alonso-Gómez et al., 2004; Baeza et al., 2004; Sastre et al., 2000), but an Italian group obtained positive

\footnotetext{
${ }^{1}$ Fundación para la Investigación Biomédica and ${ }^{2}$ Immunology Department, Hospital Carlos III, Madrid, Spain.

${ }^{3}$ Instituto del Frío, CSIC, Madrid, Spain.
} 
results in prick-by-prick and patch tests using live, cooked, and frozen A. simplex larvae (Ventura et al., 2008).

To assess if fish is parasitized by anisakid larvae, current methods include visual inspection under white or ultraviolet light. This method is time consuming and not sensitive if the worms are located deep within the fish fillets (Stormo et al., 2007). An enzymatic degradation of the fillets is a more effective method (Levsen et al., 2005), but it destroys the fish. To our knowledge, some molecular methods, such as the polymerase chain reaction, have only been used to identify the anisakid species (Farjallah et al., 2008); as far as we know, there has been one attempt to measure $A$. simplex allergens by immunological methods, but only in A. simplex extracts and commercial fish extracts, to standardize these reagents used in the allergy diagnosis (Arilla et al., 2008).

The objective of our work was to develop a sensitive method to extract and measure $A$. simplex proteins directly from fresh or processed fish muscle and fish derivatives, and to characterize their allergenicity.

\section{Materials and Methods}

\section{Fish sample preparation}

Fresh hakes (Merluccius merluccius), anchovies (Engraulis encrasicholus), sardines (Sardina pilchardus), red mullets (Mullus barbatus), blue whitings (Micromesistius potassou), clams (Tapes decussatus), shrimps (Parapanaeus longirostris), and cockles (Cerastoderma edule) were obtained in local markets.

To study the effects of cooking on the A. simplex allergenicity, four infested hake belly flaps were divided into two parts. One of them was immediately processed to extract the possible $A$. simplex allergens, while the other was boiled for 30 minutes in distilled water $(1: 1, w: v)$ before being processed. The water in which the fish was boiled (fish stock) was also studied.

To study the effects of long-term frozen storage in $A$. simplex antigenicity and allergenicity, 34 hakes were caught by trawling from the fishing grounds of the Little Sole Bank in the Bay of Biscay during the 310 research cruise of the German research vessel Walther Herwig III in March 2008. Skin off fillets (dorsal and belly flaps) were vacuum packed, frozen onboard in a blast freezer at $-20^{\circ} \mathrm{C}$, and stored until analyzed at $-20^{\circ} \mathrm{C} \pm 2^{\circ} \mathrm{C}$. Guts from each hake were digested for $\geq 4$ hours at $37^{\circ} \mathrm{C}$ in Solution A $(0.5 \%[\mathrm{w} / \mathrm{v}$ ] pepsin, $0.063 \mathrm{M} \mathrm{HCl}$, and $200 \mathrm{~g}$ of gut $/ \mathrm{L}$ of solution $\mathrm{A}$ ), the residue was strained and washed in $0.9 \%$ $\mathrm{NaCl}$ and $A$. simplex larvae were counted. Hakes were classified according the viscerae parasitization rate: the count less than $300 \mathrm{~A}$. simplex larvae was considered low parasitization, between 300 and 900 larvae was considered medium parasitization, and more than 900 larvae was considered high parasitization. The belly flaps from 12 hakes (3 low parasitized, 4 medium parasitized, and 5 highly parasitized) were thawed and studied 2 weeks after capture; 11 (3 low, 4 medium, and 4 highly parasitized) were thawed and studied 4 months after capture; the other 11 ( 3 low, 4 medium, and 4 highly parasitized) were thawed and studied 11 months after capture.

\section{A. simplex extracts}

Live $A$. simplex larvae were obtained manually from blue whiting viscera, washed twice, and stored at $-20^{\circ} \mathrm{C}$. Five grams of larvae were ground in a mortar, diluted in $5 \mathrm{~mL}$ of phosphate-buffered saline, and sonicated for 5 seconds. Extracts were incubated at room temperature for 30 minutes before centrifuging them for 10 minutes at $16000 \mathrm{~g}$ to obtain a crude extract, whose protein content was measured using Protein Quantification Kit-Rapid (Fluka; Sigma-Aldrich Inc, St. Louis, MO).

\section{Patients' sera}

Patients were considered $A$. simplex sensitized if allergic symptoms elicited within 12 hours after the ingestion of fish and skin prick test and serological test (Immuno-CAP; Phadia, Uppsala, Sweden) were positive for $A$. simplex and specific IgE against fish was not detectable. A pool of six sera from patients with anti-A. simplex specific IgE $>17.5 \mathrm{kUA} / \mathrm{L}$ (class 4 or higher) were pooled for revealing the $\mathrm{IgE}$ immunoblots.

A pool of six nonatopic sera was used as experiment control.

\section{Proteins extraction method}

Skin, viscera, and bones were taken out from fish before the protein extraction. Shell was also taken out from shellfish before processing it.

Fish fillets $(10 \mathrm{~g})$ were minced $1: 3(\mathrm{w}: \mathrm{v})$ in a TBS solution using an Ultra-Turrax T25 (Janke \& Kunkel IKALabortechnik, Staufen, Germany). The resulting mixture was sonicated in a Microson ultrasonic cell disruptor XL (Misonix, Farmingdale, NY) and centrifuged $\left(6000 g, 20^{\circ} \mathrm{C}, 30\right.$ minutes). The pellet was discarded and the supernatant was acidified to $\mathrm{pH}<1$ by adding $0.075 \mathrm{mM}$ (final concentration) $\mathrm{HCl}$, incubated for 15 minutes at room temperature, neutralized to $\mathrm{pH} 7$ with $\mathrm{NaOH}$, and centrifuged $\left(16000 \mathrm{~g}, 30\right.$ minutes, $\left.20^{\circ} \mathrm{C}\right)$. The pellet was discarded and the supernatant was analyzed.

\section{Sodium dodecyl sulphate-polyacrylamide gel electrophoresis and immunoblotting}

Protein electrophoresis was performed on 16\% Tris-tricine minigels according to standard procedures. After electrophoresis, proteins were transferred to nitrocellulose by overnight diffusion, and the membranes were revealed using polyclonal anti- $A$. simplex crude extract (AC) or antirecombinant Ani s 4 (A4) rabbit antisera (to detect $A$. simplex antigens), or a pool of $A$. simplex-sensitized human sera (to $\operatorname{detect} A$. simplex allergens), and the corresponding secondary antisera, according to previously published methods (Moneo et al., 2000; Rodriguez-Mahillo et al., 2007). Color developing with 5-bromo-4-choro-3-indolyl phosphate-nitro blue tetrazolium (BCIP-NBT) was performed for 30 minutes when using the polyclonal rabbit antisera and for 5 hours when using the pool of human sera.

Negative controls with a preimmune antiserum and a pool of nonatopic human sera were performed.

A result was considered positive if the band pattern of a fish sample was consistent with that obtained for an Anisakis simplex crude extract.

When needed, membranes were scanned and measured by densitometry using Quantity One software (Bio-Rad, Hercules, CA).

\section{Quantification of A. simplex antigens in fish}

Five microliters of the positive samples was dotted in duplicate to a nitrocellulose membrane and dried for 30 minutes 
at $37^{\circ} \mathrm{C}$. After blocking, membranes were subsequently incubated with polyclonal A4 rabbit antiserum (1/10000 dilution, 1 hour, room temperature) and alkaline-phosphataselabeled goat anti-rabbit IgG (1/5000 dilution, 30 minutes, room temperature), and revealed for 30 minutes with BCIPNBT.

A reference curve was made in duplicate, dotting 5, 2.5, $1.25,0.62,0.31$, and $0 \mu \mathrm{g}$ of an A. simplex crude extract.

Membranes were scanned and we used Quantity One software (Bio-Rad) to define the boundaries of protein dots, to assess pixel number and density, and to obtain final numerical data for quantifying.

\section{Recovery rate and detection limit}

Anisakis-free fish fillets $(10 \mathrm{~g})$ were injected with $20 \mu \mathrm{L}$ of decreasing concentrations of $A$. simplex crude extract (200, $100,50,25,0 \mu \mathrm{g} / \mathrm{mL}$ ) and recombinant Ani s 4 (rAni s 4) (10, 5, $2.5,1.25,0 \mu \mathrm{g} / \mathrm{mL}$ ) obtained as described (Rodriguez-Mahillo et al., 2007). After an incubation of 10 minutes at room temperature, proteins were extracted and studied as described above. Assay controls were performed using a rabbit preimmune serum and a mixture of six nonatopic patients' sera. These extractions were performed in triplicate.

\section{Basophil activation test}

Patients blood $(100 \mu \mathrm{L})$ was incubated as described (Gonzalez-Munoz et al., 2005), with $1 \mu \mathrm{g} / \mathrm{mL}$ of $A$. simplex crude and mature hake (fresh, boiled, or frozen), red mullet and juvenile hake (weight $\leq 150 \mathrm{~g}$ ) extracts, and with hake stock. To analyze basophil activation, cells were stained with $20 \mu \mathrm{L}$ CD63(IgG1)-FITC/CD123(IgG1)-PE/HLA-DR(IgG2a)-PerCP reagent mixture (BD Biosciences, Erembodegem, Belgium) for 20 minutes. Activation was determined by flow cytometry measuring the increase of the basophils CD63 expression when incubated with the fish extracts, using a FACSort Cytometer (BD Biosciences) equipped with an argon laser $(488 \mathrm{~nm})$. PMT voltages (V) were as follows: FL1 = 570, FL2 = 539 , and FL3 $=680$.

Nonsensitized patient blood was tested as assay control.

\section{Statistics}

Statistical analysis was performed using SPSS 13.0 software (SPSS, Inc., Chicago, IL). Variables are described as median and interquartile range. Pearson's correlation coefficient is given to measure the association between quantitative variables.

\section{Results}

\section{Evaluation of the extraction-detection method}

Blue whitings and anchovies with no $A$. simplex larvae were injected with decreasing concentrations of a mixture of A. simplex crude extract and rAni s 4 . After the protein extraction, the intensity of the blots revealed with the AC and A4 antisera correlated for each sample $(r=0.889, p<0.001)$. We recovered $82.5 \%$ (interquartile range $59.25 \%-100 \%$ ) of the $A$. simplex crude extract injected in fish.

When testing blue whitings, we could detect $200 \mathrm{ng}$ A. simplex crude extract/g of fish and $2.5 \mathrm{ng}$ of Ani s $4 / \mathrm{g}$ of fish. When testing anchovies, we could detect $625 \mathrm{ng} A$. simplex crude extract $/ \mathrm{g}$ of fish and $5 \mathrm{ng}$ of Ani s $4 / \mathrm{g}$ of fish.
A mixture of $A$. simplex-sensitized patients' sera did not detect any band even when the highest concentration of A. simplex extract $(0.4 \mu \mathrm{g} / \mathrm{g}$ of fish) was injected.

Negative controls using preimmune antisera and a pool of nonatopic human sera gave completely negative immunoblots (data not shown).

\section{Detection of A. simplex antigens in different fish species}

Several fish and shellfish species were tested for $A$. simplex antigens and allergens detection (Table 1). Neither the rabbit antisera nor the pool of $A$. simplex-sensitized patients' sera were able to detect any band in immunoblot when clams, shrimps, or cockles were tested. No A. simplex antigens or allergens were detected in sardines or red mullets. We could detect $A$. simplex antigens and allergens in mature hakes $(>1500 \mathrm{~g})$ but not in juvenile $(<150 \mathrm{~g})$ hakes. We could also find $A$. simplex antigens in anchovies.

When $A$. simplex antigens were detected by immunoblot, using rabbit anti-AC antiserum (Fig. 1), the extracts from parasitized fish had several antigenic bands with estimated molecular weights ranging from 9 to more than $75 \mathrm{kDa}$. When using the A4 antiserum to reveal the immunoblot (Fig. 1), a band around $10 \mathrm{kDa}$ identified as A4 was also detected.

When $A$. simplex allergens were detected by immunoblot, using a pool of sensitized patients' sera (Fig. 1), several allergenic proteins with molecular weights from 10 to more than $75 \mathrm{kDa}$ were detected.

The intensity of the bands was proportional in all the immunoblots: the most intense extracts in the rabbit immunoblot revealed with the AC antiserum were also the most intense extracts in the rabbit immunoblot revealed with the A4 antiserum and the human immunoblot.

\section{Quantification of A. simplex proteins in parasitized fish}

When positive by immunoblot, the $A$. simplex antigens in fish samples were quantified by dotblot, spotting $5 \mu \mathrm{L}$ of the fish extracts in a nitrocellulose membrane and comparing the intensity of the resulting dots with a reference curve made spotting decreasing concentrations of an A. simplex crude extract. The coefficient of variation between the intensity of the pair of dots proceeding from the same sample was $<10 \%$.

\section{Table 1. Anisakis simplex Proteins Detection AND QuANTIFICATION IN Different Fish} AND SHELlFish SPECIES

\begin{tabular}{lccc}
\hline Fish/shellfish & $\begin{array}{c}\text { Tested } \\
(\mathrm{n})\end{array}$ & $\begin{array}{c}\text { Positive } \\
(\mathrm{n})\end{array}$ & $\begin{array}{c}\mu \mathrm{g} \text { A. simplex antigens } / g \\
\text { of fish }[M(\mathrm{IQR})]\end{array}$ \\
\hline Clam & 12 & 0 & $\mathrm{NM}$ \\
Shrimp & 12 & 0 & $\mathrm{NM}$ \\
Cockle & 12 & 0 & $\mathrm{NM}$ \\
Sardine & 22 & 0 & $\mathrm{NM}$ \\
Red mullet & 10 & 0 & $\mathrm{NM}$ \\
Mature hake & 46 & 44 & $319.67(183.54-622.00)$ \\
Juvenile hake & 20 & 0 & $\mathrm{NM}$ \\
Anchovie & 52 & 10 & $462.92(99.23-1752.25)$ \\
\hline
\end{tabular}

Fish and shellfish were obtained at local markets from Madrid (Spain). M, median; IQR, interquartile range; NM, not measured. 


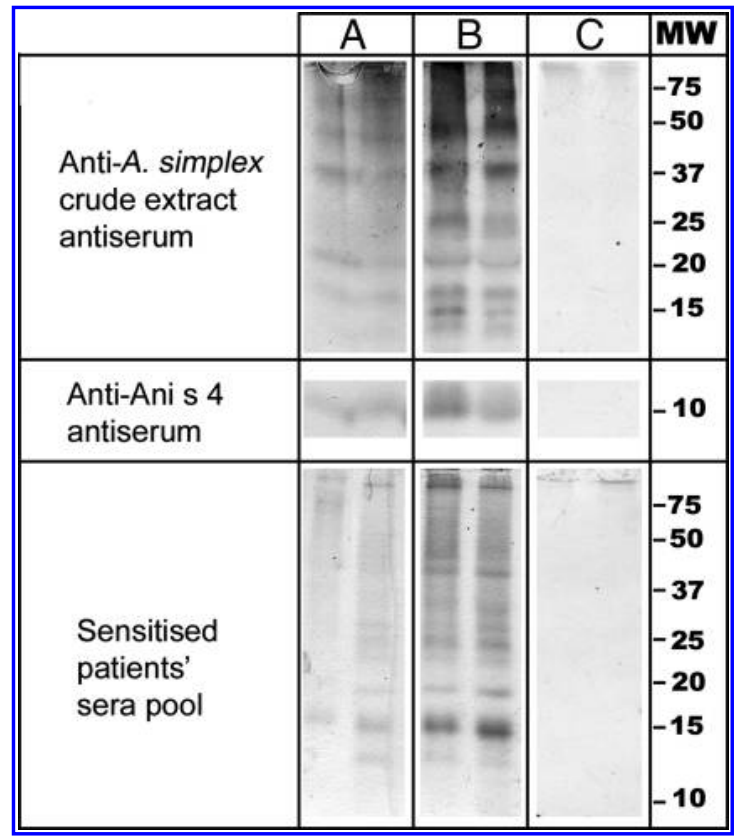

FIG. 1. Immunoblots of two anchovies (A), two adult (B), and two juvenile $(\mathrm{C})$ hakes extracts revealed with polyclonal anti-Anisakis simplex crude extract, polyclonal anti-rAni s 4 antisera or a pool of sensitized patients' sera. Molecular weights $(\mathrm{kDa})$ are indicated.

The A. simplex antigens content in positive hakes and anchovies are summarized in Table 1.

\section{Effect of cooking on the A. simplex allergens}

Boiling parasitized hakes did not destroy the antigenic recognition, but it altered the recognition pattern by the polyclonal antisera (Fig. 2). Some of the A. simplex antigens, Ani s 4 among them, were detected in the water used for boiling the hakes (hake stock). When measuring the intensity of the band corresponding to Ani s 4, boiling the fish led to a reduction of $54.03 \%$ in the Ani s 4 band's intensity in the immunoblot.

\section{Study of the long-term frozen storage of fish in A. simplex proteins}

Antigens and allergens were detected in the muscle from all the samples, even in the less parasitized group stored 11 months (Fig. 3).

The A. simplex larvae in guts for each group of hakes, expressed as median and interquartil range, was 22 and 22154.5 for low parasitized hakes, 468.5 and 320-639.75 for medium parasitized hakes, and 1191 and 1092-1677 for high parasitized hakes. No relation was obtained between the parasitization rate in guts and the intensity of the band corresponding to Ani s 4 in fish muscle.

\section{Basophil activation}

The basophils from four $A$. simplex-sensitized patients (Table 2) were activated by $A$. simplex crude extract, by fresh, boiled, and frozen adult hake extracts, and by the hake stock, whereas the red mullet extracts were not able to activate them $(<5 \%$ of activated basophils). The basophils of two

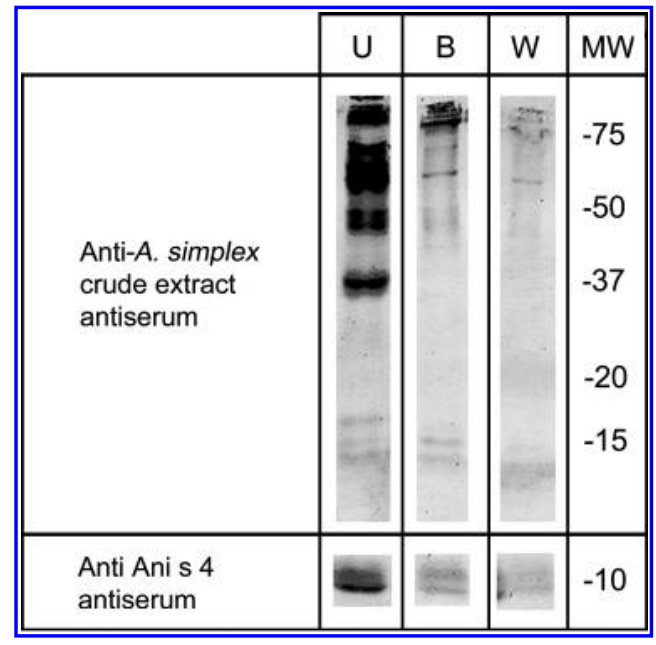

FIG. 2. Immunoblots revealed with an anti- $A$. simplex crude extract antiserum and an anti-rAni s 4 antiserum of untreated (lane U), and boiled (lane B) hake belly flaps. The water used for boiling was also tested (lane W). Molecular weights $(\mathrm{kDa})$ are indicated.

nonsensitized patients were not activated by any of the extracts ( $<5 \%$ of activated basophils) (data not shown).

\section{Discussion}

In this article, we describe a new and simple method to extract and detect $A$. simplex antigens in fish muscle and its application in fresh, frozen, and cooked fish, and even in testing the water used to boil fish.

If we assume that the presence of Anisakis simplex antigens implies presence of the parasite in fish, the use of a polyclonal anti- $A$. simplex crude extract antiserum led us to discriminate

\begin{tabular}{|c|c|c|c|c|c|c|c|c|}
\hline Frozen storage & & weel & & & mon & ths & 11 months & \\
\hline Parasitisation rate & & $\mathrm{M}$ & $\mathrm{H}$ & & M & $\mathrm{H}$ & $\mathrm{L} M \mathrm{M}$ & MW \\
\hline $\begin{array}{l}\text { Anti- } A \text {. simplex } \\
\text { crude extract } \\
\text { antiserum }\end{array}$ & E & $\begin{array}{l}\text { e } \\
= \\
=\end{array}$ & & & 풀 & 3 & $=$ & $\begin{array}{l}-75 \\
-50 \\
-37 \\
-25 \\
-20 \\
-15\end{array}$ \\
\hline $\begin{array}{l}\text { Anti-Ani s } 4 \\
\text { antiserum }\end{array}$ & - & $=$ & e & - & a & $=$ & 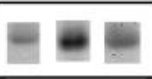 & -10 \\
\hline $\begin{array}{l}\text { Sensitised } \\
\text { patients' } \\
\text { sera pool }\end{array}$ & $\begin{array}{l}m \\
5 \\
5\end{array}$ & $=$ & $\begin{array}{l}\text { m } \\
= \\
=\end{array}$ & $=$ & 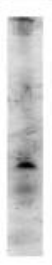 & - & $\frac{1}{3}$ & $\begin{array}{l}-75 \\
-50 \\
-37 \\
-25 \\
-20 \\
-15 \\
-10\end{array}$ \\
\hline
\end{tabular}

FIG. 3. Immunoblots revealed with an anti- $A$. simplex crude extract antiserum, an anti-rAni s 4 antiserum, and a pull of $A$. simplex-sensitized patients sera of low (L), medium $(\mathrm{M})$, and highly $(\mathrm{H})$ parasitized hakes frozen stored for 2 weeks, 4 months, and 11 months. Molecular weights (kDa) are indicated. 
Table 2. Basophil Activation Percentages When Incubating Patients' Blood with an Anisakis simpleX, Fresh, Frozen $\left(-20^{\circ} \mathrm{C} \pm 2{ }^{\circ} \mathrm{C}\right.$ for 2 Weeks), ANd Cooked ( $100^{\circ} \mathrm{C}$ for 30 Minutes) Mature HaKe (Merluccius merlucCiUs) Muscle Extracts and Hake Stock $\left(100^{\circ} \mathrm{C}\right.$ for 30 Minutes)

\begin{tabular}{lcccccc}
\hline Extract & A. simplex & Fresh hake & Cooked hake & Frozen hake & Hake stock & Red mullet \\
\hline Patient 1 & 23.9 & 24.91 & 10.84 & 11.29 & 10.42 & 0.56 \\
Patient 2 & 92.47 & 72.5 & 49.36 & 60.61 & 19.74 & 1.2 \\
Patient 3 & 84.13 & 91.18 & 93.75 & 97.48 & 85.53 & 0.22 \\
Patient 4 & 87.32 & 95.18 & 64.04 & 90.43 & 44.50 & 0.59 \\
\hline
\end{tabular}

Nonparasitized red mullet (Mullus barbatus) extract was used as negative control.

between parasitized and not parasitized fish, with larvae in the intestinal tract and other viscera, excreting proteins detectable in muscle, or in the muscle itself. A. simplex proteins such as paramyosin and tropomyosin cross-react with other allergen sources such as dust mites, cockroaches, or crustaceans (Wild and Lehrer, 2005; Guarneri et al., 2007). Our extraction and detection method has proved to be free of cross-reactivities with shellfish such as shrimps, cockles, or clams, and therefore it can be used to test anisakid parasitization in shellfish.

On the other hand, using a polyclonal antiserum against one allergen, Ani s 4, in the detection of $A$. simplex antigens in fish, enabled us to quantify the total amount of $A$. simplex proteins. Quantifying one allergen to measure the content of an allergenic substance in food has been used previously with peanuts (Pomés et al., 2003).

For other common allergies, the detection tests should ensure a sensitivity of $10 \mathrm{ppm}$ for egg, $24 \mathrm{ppm}$ for peanut, 30 ppm for milk proteins, and 5 ppm for oils (Morisset et al., 2003). Our method is able to detect less than 1 ppm of the allergen Ani s 4, whose sensitization has been associated to lifethreatening symptoms in allergic patients (Moneo et al., 2000; Rodriguez-Mahillo et al., 2007). This limit of detection would allow to determine, in a more in-depth study, if certain species of fish are not parasite allergen sources. Therefore, sensitized patients who report allergic episodes after properly cooked or canned fish intake could reintroduce fish in their diets.

Boiling and freezing parasitized fish did not destroy the allergenic epitopes of some $A$. simplex proteins, and after the thermal treatments the $A$. simplex allergens were present in parasitized fish in enough concentration to activate basophils of sensitized patients, as demonstrated in the basophil activation tests. Part of these allergens are also preserved in the fish stock and, again, in enough amounts to activate basophils. Health Authorities recommend freezing fish to be consumed raw to kill the larvae and, therefore, avoid the risks of parasitization and new sensitization. However, our data suggested that consuming properly cooked or frozen fish contaminated with Anisakis allergens, or fish stock from parasitized fish, can represent a health risk for some patients sensitized to allergens resistant to heat and freezing, such as these allergens that are not eliminated during the thermal treatments.

We previously described the heat resistance of some of the A. simplex allergens (Caballero and Moneo, 2004; Moneo et al., 2007), but, as far as we know, this is the first time that A. simplex allergens have been extracted and detected in boiled fish and in the hake stock. Although some experts in this field consider that the relationship between the ingestion of frozen, properly cooked, or canned fish and the development of allergic symptoms is not demonstrated, several articles in literature describe how patients describe symptoms after eating these products (Audicana et al., 2002; Santaolalla, 2006; Moneo et al., 2007; Ventura et al., 2008). The data obtained in this work support this fact.

The A. simplex antigens and allergens in hake muscle are preserved when fish are stored long-term, being detectable by polyclonal rabbit antisera and sensitized human sera at least 11 months after fish capture and freezing. This finding suggests that highly sensitized patients may jeopardize their health by consuming fish frozen for months in a standard industrial or domestic freezer. A. simplex migration from viscera to muscle after or before the death of the fish is still a matter of debate (Chai et al., 2005). Although it was not the aim of our study, we could ascertain that $A$. simplex larvae also migrate from the intestine to the muscle of hakes before the death of the fish, as Anisakis larvae were found in muscle, mainly in the belly flaps, in hakes eviscerated immediately after capture. After measuring the density of the immunoblot bands corresponding to Ani s 4, we could not find a relation between the quantity of $A$. simplex larvae in viscera and the amount of antigens and allergens in the musculature of hakes, supporting the lack of relation between parasitization rates in viscera and muscle found by other authors (Herreras et al., 2000; Valero et al., 2006).

Although it was not the purpose of this study, and therefore the number of fish of different species studied was limited, and again assuming that the presence of Anisakis simplex antigens means presence of the parasite, the parasitization prevalence that we have found is consistent with literature surveys. Researches have reported allergic symptoms related to sardine consumption (Ventura et al., 2008), but we could not find $A$. simplex parasitizing sardines. Other authors could not find A. simplex in sardines either (de la Torre Molina et al., 2000; Rello et al., 2008). We could find Anisakis antigens in $19.2 \%$ of the anchovies tested. Parasitization prevalence in anchovies described in literature range from 1.4\% (anchovies from the Alboran Sea) to $21.9 \%$ (anchovies from the Ligurian Sea) (Rello et al., 2009). Although a prevalence of up to $24.5 \%$ of Anisakis simplex in red mullets from the Ligurian Sea has been described (Manfredi et al., 2000), we could not detect Anisakis in any of the red mullets tested. Other authors could not find $A$. simplex in red mullets either (de la Torre Molina et al., 2000). We found A. simplex allergens in $95.6 \%$ of the hakes tested, which is a higher percentage than described in the literature (de la Torre Molina et al., 2000; Valero et al., 2006).

Benefits of fish consumption are widely demonstrated. Fish intake provides good-quality proteins, vitamins, minerals, and omega-3 fatty acids, which have been associated with 
cardiovascular health benefits. Nowadays, clinicians recommend $A$. simplex-sensitized patients to avoid the consumption of fish and shellfish for a certain time, in which they are deprived of these benefits. Using the method described in this article to assess the contamination with $A$. simplex allergens of the different fish species, and even the different parts of a fish, would allow establishing a detailed record of fish and shellfish that do not constitute an $A$. simplex allergen source that could be eaten by sensitized patients who do not tolerate even properly cooked or canned fish without jeopardizing their health.

\section{Conclusion}

We have developed an extraction-detection method of A. simplex proteins in fish muscle that allowed us to detect and quantify parasite antigens/allergens in fresh, frozen, and cooked fish and in fish stock, with high sensitivity and specificity. This method can be useful in the discrimination of fish products that are not an $A$. simplex allergen source and therefore can be safely consumed with low or no risk for sensitized patients.

\section{Acknowledgments}

This work has been partially funded by the Spanish projects AGL2005-05699-C02-01/02ALI and AGL2009-12485-C03-03. Ana I. Rodriguez-Mahillo is beneficiary of the contract CA07/00046 from the Instituto de Salud Carlos III, Ministerio de Ciencia e Innovación, Spain. Thanks are due to Dr. Horst Karl for his help provided with sample handling. The research work related to the long-term frozen storage of hakes has been undertaken in collaboration with the Max Rubner Institute, Hamburg, Germany, under the cooperative German-Spanish research on nematodes in fish species on the Bay of Biscay. Suzanne Nicol assisted in editing the English of this article.

\section{Disclosure Statement}

No competing financial interests exist.

\section{References}

Alonso-Gómez A, Moreno-Ancillo A, López-Serrano MC, Suarez-de-Parga JM, Daschner A, Caballero MT, Barranco P, and Cabañas R. Anisakis simplex only provokes allergic symptoms when the worm parasitises the gastrointestinal tract. Parasitol Res 2004;93:378-384.

Añíbarro B, Seoane FJ, and Múgica MV. Involvement of hidden allergens in food allergic reactions. I Investig Allergol Clin Immunol 2007;17:168-172.

Arilla MC, Ibarrola I, Martínez A, Monteseirín J, Conde J, and Asturias JA. An antibody-based ELISA for quantification of Ani s 1, a major allergen from Anisakis simplex. Parasitology 2008;135:1-6.

Audicana MT, Ansotegui IJ, de Corres LF, and Kennedy MW. Anisakis simplex: dangerous-dead and alive? Trends Parasitol 2002;18:20-25.

Audicana MT and Kennedy MW. Anisakis simplex: from obscure infectious worm to inducer of immune hypersensitivity. Clin Microbiol Rev 2008;31:360-379.

Baeza ML, Rodríguez A, Matheu V, Rubio M, Tornero P, de Barrio M, Herrero T, Santaolalla M, and Zubeldia JM. Characterization of allergens secreted by Anisakis simplex parasite: clinical relevance in comparison with somatic allergens. Clin Exp Allergy 2004;34:296-302.

Bock SA, Munoz-Furlog A, and Sampson HA. Fatalities due to anaphylactic reactions to foods. I Allergy Clin Immunol 2001;107:191-193.

Brown AF, McKinnon D, and Chuck K. Emergency department anaphylaxis: a review of 142 patients in a single year. J Allergy Clin Immunol 2001;108:861-866.

Caballero ML and Moneo I. Several allergens from Anisakis simplex are highly resistant to heat and pepsin treatments. Parasitol Res 2004;93:248-251.

Chai JY, Murrell KD, and Lymbery AJ. Fish-borne parasitic zoonoses: status and issues. Int J Parasitol 2005;35:1233-1254.

Clark S, Bock SA, Gaeta TJ Brenner BE, Cydulka RK, and Camargo CA. Multicenter study of emergency department visits for food allergies. J Allergy Clin Immunol 2004;113:347-352.

Daschner A, Alonso-Gomez A, Cabañas R, Suarez-de-Parga JM, and Lopez-Serrano MC. Gastroallergic anisakiasis: borderline between food allergy and parasitic disease: clinical and allergologic evaluation of 20 patients with confirmed acute parasitism by Anisakis simplex. I Allergy Clin Immunol 2000;105: 176-181.

de la Torre Molina R, Pérez Aparicio J, Hernández Bienes M, Jurado Pérez R, Martínez Ruso A, and Morales Franco E. Anisakiasis in fresh fish sold in the north of Córdoba. Rev Esp Salud Publica 2000;74:517-526.

Farjallah S, Slimane BB, Busi M, Paggi L, Amor N, Blel H, Said K, and $\mathrm{D}^{\prime}$ Amelio S. Occurrence and molecular identification of Anisakis spp. from the North African coasts of Mediterranean Sea. Parasitol Res 2008;102:371-379.

Gonzalez-Munoz M, Luque R, Nauwelaers F, and Moneo I. Detection of Anisakis simplex-induced basophil activation by flow cytometry. Cytometry B Clin Cytom 2005;68:31-36.

Guarneri F, Guarneri C, and Benvenga S. Cross-reactivity of Anisakis simplex: possible role of Ani s 2 and Ani s 3. Int J Dermatol 2007;46:146-150.

Herreras MV, Aznar FJ, Balbuena JA, and Raga JA. Anisakid larvae in the musculature of the Argentinean hake, Merluccius hubbsi. J Food Prot 2000;63:1141-1143.

Levsen A, Lunestad BT, and Berland B. Low detection efficiency of candling as a commonly recommended inspection method for nematode larvae in the flesh of pelagic fish. I Food Prot 2005;68:828-832.

Manfredi MT, Crosa G, Galli P, and Ganduglia S. Distribution of Anisakis simplex in fish caught in the Ligurian Sea. Parasitol Res 2000;86:551-553.

Moneo I, Caballero ML, Gómez F, Ortega E, and Alonso MJ. Isolation and characterization of a major allergen from the fish parasite Anisakis simplex. I Allergy Clin Immunol 2000;106: 177-182.

Moneo I, Caballero ML, Rodriguez-Perez R, Rodriguez-Mahillo AI, and Gonzalez-Muñoz M. Sensitization to the fish parasite Anisakis simplex: clinical and laboratory aspects. Parasitol Res 2007;101:1051-1055.

Morisset M, Moneret-Vautrin DA, Kanny G, et al. Thresholds of clinical reactivity to milk, egg, peanut and sesame in immunoglobulin E-dependent allergies: evaluation by double-blind or single-blind placebo-controlled oral challenges. Clin Exp Allergy 2003;33:1046-1051.

Pomés A, Helm RM, Bannon GA, Burks AW, Tsay A, and Chapman D. Monitoring peanut allergen in food products by measuring Ara h. J Allergy Clin Immunol 2003;111:640-645.

Rello FJ, Adroher FJ, Benítez R, and Valero A. The fishing area as a possible indicator of the infection by anisakids in anchovies 
(Engraulis encrasicholus) from south western Europe. Int J Food Microbiol 2009;129:277-281.

Rello FJ, Adroher FJ, and Valero A. Hysterothylacium aduncum, the only anisakid parasite of sardines (Sardina pilchardus) from the southern and eastern coasts of Spain. Parasitol Res 2008; 104:117-121.

Rodriguez-Mahillo AI, Gonzalez-Muñoz M, Gomez-Aguado F, Rodriguez-Perez R, Corcuera MT, Caballero ML, and Moneo I. Cloning and characterisation of the Anisakis simplex allergen Ani s 4 as a cysteine-protease inhibitor. Int J Parasitol. 2007;37: 907-917.

Sampson HA. Anaphylaxis and emergency treatment. Pediatrics 2003;111:1601-1608.

Santaolalla M. Estudio epidemiológico de las manifestaciones clínicas de los hallazgos de laboratorio y de la eficacia del tratamiento, en la alergia al Anisakis simplex [tesis doctoral]. Facultad de Medicina, Universidad del País Vasco/EHU, Spain, 2006. [in Spanish.]

Sastre J, Lluch-Bernal M, Quirce S, Arrieta I, Lahoz C, Del Amo A, Fernández-Caldas E, and Marañón F. A double-blind, placebo-controlled oral challenge study with lyophilized larvae and antigen of the fish parasite, Anisakis simplex. Allergy 2000;55:560-564.

Smith V, Cameron PA, and Rainer TH. Anaphylaxis presentations to an emergency departement in Hong Kong: incidence and predictors of biphasic reactions. J Emerg Med 2005;28: 381-388.
Stormo SK, Sivertsen AH, Heia K, Nilsen H, and Elvevoll E. Effects of single wavelength selection for Anisakid roundworm larvae detection through multispectral imaging. J Food Prot 2007;70:1890-1895.

Uguz A, Lack G, Pumphrey R, Ewan P, Warner J, Dick J, Briggs $\mathrm{D}$, Clarke S, Reading D, and Hourihane J. Allergic reactions in the community: a questionaire survey of members of the anaphylaxis campaign. Clin Exp Allergy 2005;35:746-750.

Valero A, Lopez-Cuello MDM, Benitez R, and Adroher FJ. Anisakis spp. in European hake, Merluccius merluccius from the Atlantic off north-west Africa and the Mediterranean off southern Spain. Acta Parasitol 2006;51:209-213.

Ventura MT, Tummolo RA, Di Leo E, D’Ersasmo M, and Arsieni A. Immediate and cell-mediated reactions in parasitic infections by Anisakis simplex. I Investig Allergol Clin Immunol 2008;18:253-259.

Wild LG and Lehrer SB. Fish and shellfish allergy. Curr Allergy Asthma Rep 2005;5:74-79.

Address correspondence to: Ana Isabel Rodríguez-Mahillo, Ph.D. Fundación para la Investigación Biomédica Hospital Carlos III c/Sinesio Delgado 10, 28029 Madrid Spain

E-mail: anai_rm@yahoo.es 